This article was downloaded by: [Massey University Library]

On: 24 February 2011

Access details: Access Details: [subscription number 907449176]

Publisher Routledge

Informa Ltd Registered in England and Wales Registered Number: 1072954 Registered office: Mortimer House, 3741 Mortimer Street, London W1T 3JH, UK

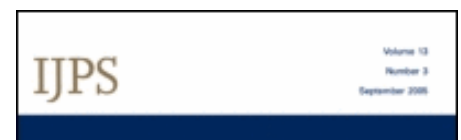

\title{
International Journal of Philosophical Studies
}

Publication details, including instructions for authors and subscription information:

http://www.informaworld.com/smpp/title $\sim$ content=t713685587

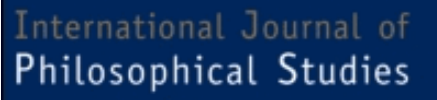

\author{
McDowell's Alternative Conceptions of the World \\ William Fish'; Cynthia Macdonald ${ }^{\mathrm{b}}$ \\ ${ }^{a}$ Massey University, New Zealand ${ }^{\mathrm{b}}$ Queen's University, Belfast, UK \\ Online publication date: 23 February 2011
}

R prostedse

To cite this Article Fish, William and Macdonald, Cynthia(2011) 'McDowell's Alternative Conceptions of the World',

International Journal of Philosophical Studies, 19: 1, 87 - 94

To link to this Article: DOI: $10.1080 / 09672559.2011 .539368$

URL: http://dx.doi.org/10.1080/09672559.2011.539368

\section{PLEASE SCROLL DOWN FOR ARTICLE}

\footnotetext{
Full terms and conditions of use: http://www.informaworld.com/terms-and-conditions-of-access.pdf

This article may be used for research, teaching and private study purposes. Any substantial or systematic reproduction, re-distribution, re-selling, loan or sub-licensing, systematic supply or distribution in any form to anyone is expressly forbidden.

The publisher does not give any warranty express or implied or make any representation that the contents will be complete or accurate or up to date. The accuracy of any instructions, formulae and drug doses should be independently verified with primary sources. The publisher shall not be liable for any loss, actions, claims, proceedings, demand or costs or damages whatsoever or howsoever caused arising directly or indirectly in connection with or arising out of the use of this material.
} 


\section{Discussion}

\section{McDowell's Alternative Conceptions of the World}

\section{William Fish $^{a}$ and Cynthia Macdonald}

\section{Introduction}

In 'On McDowell's Identity Conception of Truth' (Fish and Macdonald, 2007) we presented a pair of identity claims which we suggested makes sense of John McDowell's remarks about the contents of true thoughts and represents his considered opinion on the matter. Among the various things that McDowell claims about the contents of true thoughts, two themes stand out: (1) that the content of a true thought is a fact; (2) that facts are constituents of the world. Some (for example Dodd, 1995) have argued that (1) and (2) are inconsistent on the following grounds. As McDowell understands things, (1) commits us to a Fregean view of facts, according to which facts are senses that have senses as constituents, whereas (2) commits us to a 'robust' conception of facts, according to which facts have objects and properties as constituents. But, since senses are not objects and properties but modes of presentation of objects and properties, it is inconsistent to claim that the constituents of facts are both senses (from (1)) and objects and properties (from (2)).

In response to this apparent inconsistency, we pointed out that the claim that facts are senses that have senses as constituents indicates that there are two categories of senses: complex and atomic. Complex senses are ones that have other senses as constituents (and are of suitable complexity to serve as thought contents); simple senses are the basic, atomic senses that are the constituents of complex senses (and are basic modes of presentation). So, to be clear, rather than say that facts are senses that have senses as constituents, we should say that facts are complex senses that have atomic senses as constituents.

The question remains of how to reconcile this with the idea that facts are constituents of the world. To do this, we noted first that McDowell explicitly rejects the claim that, in order to be constituents of the world, facts must have objects and properties as constituents. He suggests instead that facts are

International Journal of Philosophical Studies

ISSN 0967-2559 print 1466-4542 online (C) 2011 Taylor \& Francis

http://www.informaworld.com

DOI: $10.1080 / 09672559.2011 .539368$ 
elements of the world 'on the natural Tractarian conception' (1999: p. 96). We then noted that, in the Tractatus, Wittgenstein also classifies facts, qua constituents of the world, into a class of simple facts and a class of complex facts. Moreover, as is the case with Fregean senses, complex facts (Tatsache) have simple facts (Sachverhalte) as constituents.

This leaves us with the following picture:

\section{Fregean senses}

Complex

Simple
Complex senses (thought contents)

Simple senses (modes of presentation)

\section{Tractarian facts}

Tatsache

Sachverhalte

Our proposal was that McDowell makes two identity claims, corresponding to the two rows in this chart: (I1) that complex senses are identical with complex facts (Tatsache) and (I2) that simple senses are identical with simple facts (Sachverhalte). We defended this view in part by showing that Sachverhalte can be seen to present objects in particular ways: the Sachverhalte that is the object's being undernourished can be seen as presenting the object as being a certain way, viz. undernourished. We think that this proposal is novel and also makes much-needed sense of the various claims that McDowell makes about the contents of true thoughts. However, there are a number of potential residual difficulties with it. In the present paper, we take the opportunity to address three of these, highlighting and clarifying important features of the proposal in the process.

\section{Object Senses versus Predicate Senses}

McDowell claims that the content of a whole thought must show some level of complexity:

the content of a whole thought must do more than present what one is thinking about in a certain way (for instance in the way in which 'that tiger', in the circumstances I am imagining [i.e., in the presence of a suitably situated tiger], presents a certain tiger); it must also fix how one thinks things stand with what one is thinking about (for instance that it looks undernourished).

(2005: correspondence)

On the basis of this, we suggested that a (true) whole Fregean thought content such as $\langle$ that tiger is undernourished $\rangle$ must be complex, constituted by a mode of presentation of the tiger and a mode of presentation of undernourishedness. In line with one of our identity claims ((I2) - the claim that simple senses are identical with simple facts), we proposed that these atomic modes of presentation are identical to Tractarian Sachverhalte. Which 


\section{MCDOWELL'S ALTERNATIVE CONCEPTIONS OF THE WORLD}

Sachverhalte? The object's being a tiger and the object's being undernourished, respectively. These constituents are both simple Fregean senses/ modes of presentation (that present the object as being, in turn, a tiger and undernourished) and simple Sachverhalte/simple constituents of the world.

This proposal may look somewhat strange. After all, the initial thought content $\langle$ that tiger is undernourished $\rangle$ has subject-predicate form. On a standard reading, the Fregean senses that make up this content would be, first, a mode of presentation of an object (the tiger) and, second, a mode of presentation of a property-undernourishedness. Yet according to our proposal, the senses that constitute this content are both modes of presentation of the object.

This concern can be seen more clearly if we imagine ourselves confronted by a group of emaciated tigers. Consider the pair of contents: 〈that tiger is undernourished $\rangle$ (pointing at one tiger) and 〈that tiger is undernourished $\rangle$ (pointing at another). Naturally, we take these two contents as predicating the same property of two distinct tigers. However, on the proposal we have presented, the senses corresponding to the predicate 'is undernourished' in these two contents are actually different modes of presentation of the different objects.

Now, we agree that there is something right in the thought that the general concept of something's being undernourished - alternatively, the conception of the property of undernourishedness - can be detached from particular instances of undernourishedness. But our suggestion, based on McDowell's remarks concerning the case of colour concepts, was that the general - non de re-sense of a predicate is in fact extracted from specific de re senses. Although McDowell doesn't explicitly discuss the case of undernourishedness, he does discuss the case of colour. This is what he says about it:

A repertoire of concepts of ways of being colored ... already contains the conceptual content for a repertoire of concepts of associated objects - colors. ... One carves out, as it were, a concept of a color, an object of a certain kind, by imposing a different articulation on a thought that first comes into view as a thought to the effect that an ordinary object is colored in a certain way.

(1998: p. 416)

Here it looks as though McDowell is suggesting that our concepts of properties - colour in the case McDowell is talking about, undernourishedness in the tiger case - are carved out by imposing a different articulation on thoughts that objects bear the relevant property. So we maintain that, while there is indeed a sense in which the concept of being undernourished is detachable from particular successful episodes of thinking that something is undernourished, McDowell's view is that it is nonetheless derived from such instances. 
How might this process work? Well, suppose we think (correctly) that each tiger in the group we are confronted with is undernourished. In line with our original proposal, we suggest that the contents of these thoughts contain distinct senses/Sachverhalte corresponding to the 'is undernourished' predicate - object 1 's being undernourished, object,'s being undernourished, object $_{3}$ 's being undernourished, and so on. Still, we can, as McDowell suggests in the above quotation, 'impose a different articulation' on this array of thoughts. In imposing this different articulation, we register 'the univocity of ["is undernourished"] by associating it with a single sort of de re sense' (1984/1998: p. 220). So although each of our token thoughts contains different de re senses, we can register what these thoughts have in common by acknowledging that each contains a distinct sense of the same de re sense type. The difference between the senses lies not in their underlying nature, but rather in the ways in which they can be grouped together in imposing different articulations on our (de re) thoughts. ${ }^{1}$

\section{False Thoughts}

Thus far, we have presented the proposal by focusing on true thoughts, which enable us to assume that there will be Tractarian Sachverhalte to identify with the simple Fregean senses that constitute a complex thought content. However, it seems that we can also have false thoughts. How can our proposal be extended to these?

The first thing to note is that a putative thought can fail in different ways. For example, the putative thought that $\langle$ that tiger is undernourished $\rangle$ can fail if there is no object present at all - say if the subject is hallucinating a tiger. Call this kind of failure existence failure. Another kind of failure can occur if the subject makes a mistake about the nature of the object. Say, for example, there is an undernourished lion present, but we mistake the lion for a tiger because of light falling through bars. Here the putative thought $\langle$ that tiger is undernourished (arguably) fails as the undernourished object is not a tiger but a lion. Call this kind of failure classification failure. A third kind of failure occurs when we correctly identify an object, but falsely predicate something of that object - say, we think 〈that tiger is undernourished〉 when in fact it is perfectly well fed. This kind of failure can be called predication failure.

In a footnote in our original paper, we suggested that ' $d e$ re senses [are] unavailable to feature in the contents of false thoughts' (2007: p. 39). Although there is a sense in which this claim is correct, it is too quick. The 'false thoughts' we had in mind were those thoughts that exhibit existence failure, and we stand by the claim that, where this kind of failure is concerned, there is no possibility of identifying senses to feature in the contents of such putative thoughts. Our view is that, in cases like these, there is no thought (and a fortiori no false thought) expressed of the kind 
the subject takes there to be. Of course, this itself calls for explanation: how could the subject be so misled as to think that she is thinking a thought of a certain kind when there is no such thought to be had? We can get a sense of the kind of explanation McDowell has in mind by returning to our discussion of the extraction strategy in section 1 above.

McDowell insists that we can impose a different articulation on our thoughts by associating elements of the contents of these thoughts with 'sorts of' de re senses. Elsewhere, when he talks about subjects who are mistaken, he appeals to these de re sense sorts as follows:

Given a context, a sort of de re sense may determine a de re sense (if one cares to put it like that), or else it may determine nothing. And in the latter sort of case, according to this way of thinking, there can only be a gap - an absence - at, so to speak, the relevant place in the mind - the place where, given that the sort of de re sense in question appears to be instantiated, there appears to be a specific de re sense.

(1984/1998: p. 221)

McDowell presents this proposal in terms of first- and second-order beliefs. If a subject falsely claims that 'that tiger is undernourished', then 'the belief that makes [this] behaviour intelligible is a (false) second-order belief to the effect that the subject has, and is expressing, a first-order belief' (1977/1998: 186). In such a case, the second-order belief 'says' that the subject has a firstorder belief involving a certain sort of de re sense when, in fact, the subject lacks such a belief. Importantly, it is not the case that the subject has a firstorder belief with some kind of (false) de re sense proxy, but that the subject lacks such a belief altogether - the subject merely believes that she has such a belief.

Our view is that, in both existence and classification failures, there is no first-order belief expressed at all, since, although there may be de re 〈lion〉 and $\langle$ tiger $\rangle$ sense sorts in the particular situations envisaged, there are no specific de re senses instantiated in the mind of the thinker. Yet as we have noted, there are other ways in which thoughts might fail and, in those cases at least, we can see nothing in the picture that would preclude a position on which de re senses featured in the contents of such thoughts. This might be so in the case of (simple) predication failure. Here, a necessary condition of successfully essaying the de re singular thought - that there is a res to figure in it - is satisfied, so at least one of the Sachverhalte that would feature in the content of a successful thought remains available to feature in the content of a false thought, namely, the fact of the object's being a tiger. Given the extraction strategy for accounting for the sense of a predicate, it is possible to develop a theory of the content of false thoughts that exhibit these kinds of failure which makes an appeal to those de re senses that are available. As long as there is a suitably situated tiger present to figure in the 
object-dependent sense expressed by 'that tiger', there seems to be no reason to suppose that this sense could not figure in thoughts about that very tiger that exhibit predication failure. In the case of a thought that fails for this reason, our proposal leaves open the possibility that the predicate sense - a sort or type of sense, recall - simply will not be instantiated by the object (that tiger).

Of course, that this possibility is available doesn't guarantee that it is McDowell's considered view on the matter. Moreover, where false thoughts are concerned, expounding McDowell's views is difficult since he doesn't actually say much about such cases. Our suspicion, however, is that McDowell would in fact take the option outlined above in the case of predication failure, preferring a kind of 'disjunctive' rather than a unified treatment of failed singular de re thoughts. With this in mind, we suggest that, in cases where the subject appears to think that 〈that tiger is undernourished $>$ when it is in fact well fed, McDowell would accept the claim that the subject thinks a false thought with a content containing a de re sense corresponding to 'that tiger'.

\section{The Realm of Sense and the Realm of Reference}

The final point of clarification concerns the relationship between objects and properties - entities from the realm of Bedeutung or reference - and senses (and, by extension, the facts that they are identical with). The crucial component to understanding this, we suggest, is to recognize that, if they are to be identified with senses as we suggest, then facts cannot be inhabitants of the realm of reference and, in particular, that they cannot be further entities from the realm of reference that have objects and properties as constituents. As McDowell insists, 'to construe knowledge of the sense of an expression ... [as] knowledge of ... an entity (the sense of the expression) seems ... gratuitous' (1977/1998: p. 175).

If the realm of senses (and, by extension, facts) is not a sub-part of the realm of reference, then what is the relation between the two realms? McDowell's key insight is that the realm of facts/sense and the realm of objects/reference are in fact two alternative conceptions of one and the same world. The realm of facts/sense views the world as thinkable and is, to this extent, minddependent. When we think truly, what we think is something from the realm of facts/sense: 〈that tiger is undernourished〉, for example. What we think about when we think 〈that tiger is undernourished〉, however, is something from the mind-independent realm of reference - the tiger itself. So by thinking something from the mind-dependent realm of sense we succeed in thinking about something from the mind-independent realm of reference.

This interpretation is supported by more recent work from McDowell (2008b). In a response to Charles Travis, he characterizes the division between the realm of sense and the realm of reference in terms of 'Frege's line' - the line which 'separates non-conceptual items, on the left, from 
conceptual items, on the right' (2008b: p. 259). McDowell goes on to say the following:

[R]eason's reach coincides with the realm of thought, in something like the sense Frege attaches to 'Gedanke'; the realm of the thinkable. Travis thinks my condition leaves a piece of meat I see, a left-hand side item, outside reason's reach: unable to bear rationally on what I should think. But that is as if one supposed Frege's conception of thinkables as Sinne leaves left-hand side items - which belong in the realm of Bedeutung, not in the realm of Sinn - outside the reach of thinking. Certainly pieces of meat are not thinkables: not Gedanken or constituents of Gedanken. They belong on the left-hand side of Frege's line. But that does not put them beyond the reach of thinking.

(McDowell, 2008b: p. 260)

Here McDowell once again clearly makes the distinction between the realm of sense (on the right-hand side of Frege's line) and the realm of reference (on the left-hand side). But in doing so, he does not endorse any two-world view of facts, on the one hand, and senses, on the other. On the contrary, he goes on to state explicitly that the kinds of expressions we have been using to denote facts, 'expressions of the form "the meat's being ... on the rug", [and] "the meat's being ... underdone" ... characterize right-hand side items [or alternatively] belong in the realm of sense and hence can be thought' (2008b: p. 261). ${ }^{2}$

Of course, this insistence that there are two alternative conceptions of the world in play raises the question of how they are connected. McDowell (1999: p. 94) says that objects - elements from the realm of reference/lefthand side of Frege's line - figure in facts - elements from the realm of sense/ right-hand side of Frege's line. To understand the connection between the two realms, then, we need to know what 'figuring in' amounts to. Now, if it were to be understood in terms of constitution, then this would seem to make one conception - the one containing the constituents - prior to or more fundamental than the other. But, as we noted in our original paper, McDowell is explicit that we must "firmly distinguish "figure in" from "be a constituent of"' (1986/1998: p. 237). So 'figuring in' should not be understood in terms of constitution. Instead, we should understand it exactly as McDowell says we should: 'for an object to figure in a thought, a thinkable, is for it to be the Bedeutung associated with a Sinn that is a constituent of the thinkable' (1999: pp. 94-5). The relationship between facts - elements from the realm of sense - and objects - elements from the realm of reference - is simply that of sense to referent.

${ }^{a}$ Massey University, New Zealand

${ }^{b}$ Queen's University Belfast, $U K$ 
Notes

1 One might worry that this strategy focuses too closely on perceptual contents. In particular, it seems possible for one to think that 〈that tiger is undernourished $\rangle-$ perhaps on the basis of expert testimony - even in cases in which one does not, because one cannot, see that 〈that tiger is undernourished $\rangle$. To understand how this can be, note that McDowell insists that 'every aspect of the content of an intuition is present in a form in which it is already suitable to be the content' of a thought or judgment (2008a: p. 7). This suggests that the contents of both the thought and perception involve the same Tractarian Tatsachen: the object's being a tiger and being undernourished. Nothing precludes a given Tatsache from featuring in the content of a thought without its also featuring in the content of a perception. In such a case, the subject will merely be said to think that $\langle$ that tiger is undernourished $\rangle$ without seeing that $\langle$ that tiger is undernourished $\rangle$.

2 McDowell also goes on to make our senses-facts identity claim explicit when he says that 'the distinction [the Tractatus] insists on between facts and complex objects is in the spirit of the distinction Travis dramatizes as Frege's line, with complex objects on a counterpart to the left-hand side and facts on a counterpart to the right-hand side' (2008b: p. 264).

\section{References}

Dodd, J. (1995) 'McDowell and Identity Theories of Truth', Analysis 55(3): 160-5.

Fish, W. and C. Macdonald (2007) 'On McDowell's Identity Conception of Truth', Analysis 67(1): 36-41.

McDowell, J. (1977/1998) 'On the Sense and Reference of a Proper Name' reprinted in his Meaning Knowledge and Reality, Cambridge, MA: Harvard University Press, 1998, pp. 171-98.

(1984/1998) 'De Re Senses', reprinted in his Meaning, Knowledge and Reality, Cambridge, MA: Harvard University Press, 1998, pp. 214-27.

(1986/1998) 'Singular Thought and the Extent of Inner Space'. reprinted in his Meaning, Knowledge and Reality, Cambridge, MA: Harvard University Press, 1998, pp. 228-59. 58: 414-99.

(1998) 'Response to Peacocke', Philosophy and Phenomenological Research

(1999) 'Responses', in M. Willaschek, ed. John McDowell: Reason and Nature, Münster: LIT Verlag, pp. 91-114.

(2008a) 'Avoiding the Myth of the Given', in J. Lindgaard, (ed.) John

McDowell: Experience, Norm and Nature, Oxford: Blackwell, pp. 1-14.

- (2008b) 'Responses', in J. Lindgaard (ed.) John McDowell: Experience,

Norm and Nature, Oxford: Blackwell, pp. 200-67. 